\title{
Solar heat integrated solid oxide steam electrolysis for highly efficient hydrogen production
}

\author{
Günter Schiller, ${ }^{\star, a}$, Michael Lang ${ }^{a}$, Patric Szabo ${ }^{a}$, Nathalie Monnerie ${ }^{b}$, Henrik von Storch ${ }^{c^{\star *}}$, \\ Jan Reinhold ${ }^{\mathrm{b}^{* *}}$, Pradeepkumar Sundarraj \\ ${ }^{a}$ Deutsches Zentrum für Luft- und Raumfahrt, Institute of Engineering Thermodynamics, Pfaffenwaldring \\ 38-40, 70569 Stuttgart, Germany \\ ${ }^{b}$ Deutsches Zentrum für Luft- und Raumfahrt, Solar Research, Linder Höhe, 51147 Köln, Germany \\ ${ }^{c}$ Deutsches Zentrum für Luft- und Raumfahrt, Solar Research, Karl-Heinz-Beckurts-Str. 13, 52428 Jülich, \\ Germany \\ * Corresponding author: Günter Schiller \\ E-mail: quenter.schiller@dlr.de \\ Phone: +497116862635 \\ Fax: +497116862747
}

\begin{abstract}
Water electrolysis is considered as a suitable pathway for the production of large amounts of hydrogen to be used as energy carrier for electricity storage. Among the existing water electrolysis technologies solid oxide steam electrolysis exhibits the highest electrical efficiency. Moreover, from thermodynamic considerations the efficiency can be further increased when part of the energy demand is provided by the integration of external high temperature heat to reduce the electrical energy for the water splitting reaction. This paper reports on the successful integration of solar heat into a solid oxide electrolyzer. The experimental setup of the prototype system consisting of a solar simulator, a solar steam generator, a steam accumulator and a solid oxide electrolyzer as well as first results with regard to solar steam generation and electrochemical performance of the electrolyzer are presented. Hot steam with a maxi-
\end{abstract}

** Present address: Henrik von Storch, Christianstr. 66A, 50825 Köln, Germany Jan Reinhold, Holteistr. 26, 10245 Berlin, Germany 
mum flow rate of $5.0 \mathrm{kgh}^{-1}$ was produced with the solar steam generator. A small fraction $\left(0.58 \mathrm{kgh}^{-1}\right)$ mixed with $10 \%$ of $\mathrm{H}_{2}$ was supplied to a 12-cell solid oxide electrolyzer stack with approx. $2 \mathrm{~kW}$ electrical power. At $770{ }^{\circ} \mathrm{C}$ and a current density of $-1.25 \mathrm{Acm}^{-2}$ a steam conversion rate of $70 \%$ at $93 \%$ electrical electrolyzer efficiency was achieved.

\section{Keywords}

High temperature steam electrolysis, solar heat integration, solar steam generator, solid oxide electrolyzer, hydrogen, electrochemical and thermal behavior

\section{Introduction}

In the context of a wider use of renewable energy sources such as wind, photovoltaic and solar thermal power chemical energy carriers are needed for electricity storage due to the intermittent availability of renewable energy sources to maintain the high stability of the electricity infrastructure. Water electrolysis is considered as a promising pathway for the production of sustainable hydrogen to be used as such an energy carrier. Alkaline electrolysis, as a well proven technology for many decades, and more recently proton exchange membrane (PEM) electrolysis, are currently developed for high-performance intermittent operation in the low temperature range, below $100^{\circ} \mathrm{C}$. Compared to the low temperature electrolysis techniques, solid oxide electrolysis (SOE) operating in the high temperature regime of $700-1000{ }^{\circ} \mathrm{C}$ is a promising new technology which offers some additional advantages. The significantly higher operating temperature of solid oxide electrolysis cells (SOEC) and stacks results in faster reaction kinetics, thus enabling potentially higher energy efficiency. From a thermodynamic point of view, part of the energy demand for the endothermic water splitting reaction can be provided by high temperature heat from solar thermal power or waste heat from industrial processes, hence, significantly reducing the electric energy demand. Furthermore, high temperature electrolysis allows to not only split molecules of water steam but also that of carbon dioxide or a mixture of both to produce synthesis gas or other energy carriers such as methane or methanol by subsequent catalytic conversion [1-3]. Already during the 1980's the development of SOE was reported by W. Doenitz et al. with the "Hot Elly" project $[4,5]$ and by A.O. 
Isenberg at Westinghouse [6] on the basis of tubular solid oxide cells. Based on the progress achieved with planar solid oxide fuel cells (SOFC) in the past years renewed interest on the SOE technology appeared [7-10].

The splitting of water through high temperature electrolysis of steam uses a combination of electrical energy and heat. The chemical reactions taking place during electrolysis are as follows:

Fuel electrode:

$$
\mathrm{H}_{2} \mathrm{O}+2 \mathrm{e}^{-} \rightarrow \mathrm{H}_{2}+\mathrm{O}^{2-}
$$

Air electrode:

$$
\mathrm{O}^{2-} \rightarrow 1 / 2 \mathrm{O}_{2}+2 \mathrm{e}^{-}
$$

The following reaction results in total: $\quad \mathrm{H}_{2} \mathrm{O} \rightarrow \mathrm{H}_{2}+1 / 2 \mathrm{O}_{2}$

From thermodynamic considerations depicted in Figure 1 it is obvious that at the phase transition from liquid water to steam the enthalpy of water $\Delta \mathrm{H}^{0}$ and hence the required minimum energy for water splitting is reduced drastically. This difference of energy corresponds to the heat for evaporation $\Delta \mathrm{H}_{\text {evap. }}$ of water. Moreover, the Gibbs free enthalpy $\Delta G^{0}$ for water splitting continuously decreases with increasing temperature whereas the enthalpy $\Delta \mathrm{H}^{0}$ remains almost constant.

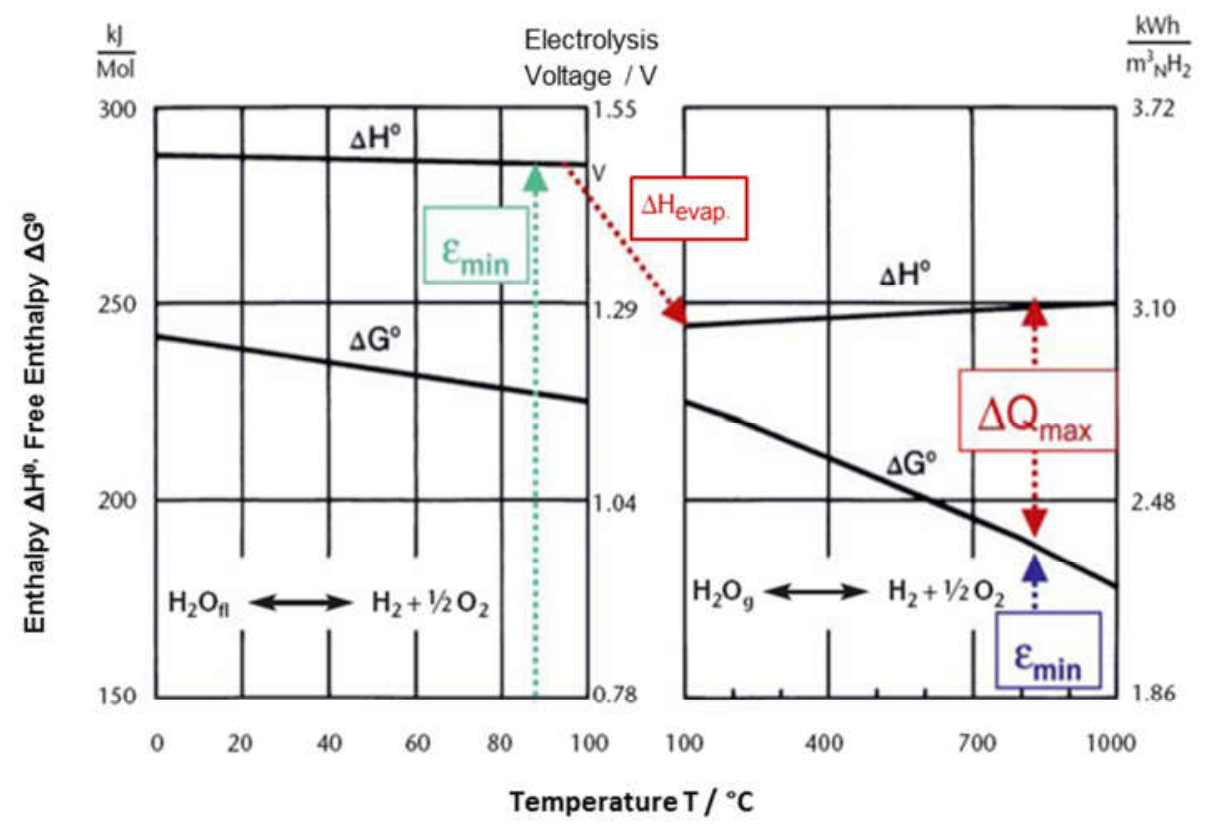

Figure 1: Thermodynamics of the water splitting reaction as a function of temperature [11] 
From these thermodynamic principles the following statements can be deduced:

- The thermodynamic cell voltage for steam electrolysis is lower than that for electrolysis of liquid water. Consequently, steam electrolysis consumes less electrical energy compared to low-temperature electrolysis processes.

- At high temperatures part of the required energy for electrolytic water splitting can be provided by heat. This heat can either be provided by external sources or is produced by the resistances of the electrolysis cell or the stack itself. The maximum amount of heat $\Delta Q_{\max }$ to be provided is given by the difference between enthalpy of water splitting $\Delta \mathrm{H}^{0}$ and Gibbs free enthalpy $\Delta \mathrm{G}^{0}$. This amount of heat integrated in the process reduces the necessary electrical energy $\varepsilon_{\min }$.

Depending on the cell voltage, three different operating modes for high-temperature steam electrolysis can be distinguished:

- Endothermal mode: The electric energy input is below the enthalpy of reaction $\Delta H^{0}$ and the cell voltage below the thermoneutral voltage. Therefore, external heat must be supplied to the system to maintain the temperature. The electricity-to-hydrogen conversion efficiency is above $100 \%$.

- Thermoneutral mode: The electricity supplied to the electrolyzer is completely used for the electrolysis reaction. The electrolyzer operates at thermal equilibrium and the electricity-to-hydrogen conversion efficiency is $100 \%$.

- Exothermal mode: The electric energy input exceeds the enthalpy of reaction corresponding to an efficiency below $100 \%$. Consequently, part of the energy will be converted into heat which will be transferred to the outlet gases.

In conventional high temperature steam electrolysis the total energy demand for water splitting is supplied as electricity. As mentioned before, high temperature heat provided by concentration of solar radiation, e.g. in solar towers, can be introduced in the SOE process for the evaporation and superheating of water [12-13]. A tube-type solar receiver as a key component for the integration of solar heat into the SOE process has been developed for operation in DLR's high flux solar simulator in Cologne [14]. In the frame 
of the DLR project "Future Fuels" the combination of this solar receiver powered by heat from the solar simulator with a solid oxide electrolyzer has been realized. This paper presents the experimental setup as well as first experimental results of the coupling of direct solar steam generation in a receiver system with high temperature steam electrolysis.

\section{Experimental}

The experimental setup of the solar heated solid oxide electrolyzer system used for hydrogen production is depicted in Figure 2. A photograph of the SOEC electrolyzer and the solar receiver (in the following called solar steam generator) in operation is shown in Figure 3. This laboratory prototype system consists of five main components: i) solar simulator, ii) solar steam generator, iii) water supply system, iv) steam accumulator, and v) solid oxide electrolyzer. Auxiliary components of the system are flow meters and valves to control the mass flow and pressure for water and steam, several temperature and pressure sensors and controllers, peripheral electrical tube heaters, mass flow controllers for the fuel gas and air of the electrolyzer, voltage supply (potentiostat) and data acquisition system.

Figure 2 shows the water/steam flow path in which the inlet water enters the solar steam generator from the water supply system. By passing through the steam generator the water is heated up to superheated steam by the incoming high energy concentrated radiation from the solar simulator. The hot steam is fed into the steam accumulator and exits the vessel when a constant pressure is reached. The outlet of the accumulator is connected to the electrolyzer and to a bypass valve. As the small laboratory scale electrolyzer cannot handle mass flows higher than $0.5 \mathrm{kgh}^{-1}$ a large fraction of the steam had to be bypassed to the environment. Due to low steam mass flows, non-optimized tube insulation and long pipes of the prototype system additional peripheral electrical heated pipes are required in order to compensate thermal losses. The system pressure and the mass flow of steam to the electrolyzer are controlled by the relative setting of two valves placed in the bypass line (steam vented to environment) and in the line to the electrolyzer. The superheated steam fed to the electrolyzer is split into $\mathrm{H}_{2}$ and $\mathrm{O}_{2}$ by the electrolysis voltage of the potentiostat. The SOEC stack was operated both in current-voltage measurement and longterm stability operation mode. Gas coolers are used to cool down both process gases to room temperature. All system components were controlled remotely by industrial programmable logic controllers 
("Siemens Simatic S7"). This ensures safe and reliable operation. In order to monitor possible system instabilities a fast data sampling rate of $1 \mathrm{~s}$ was selected. Details of the main and auxiliary components are explained in the following sections.

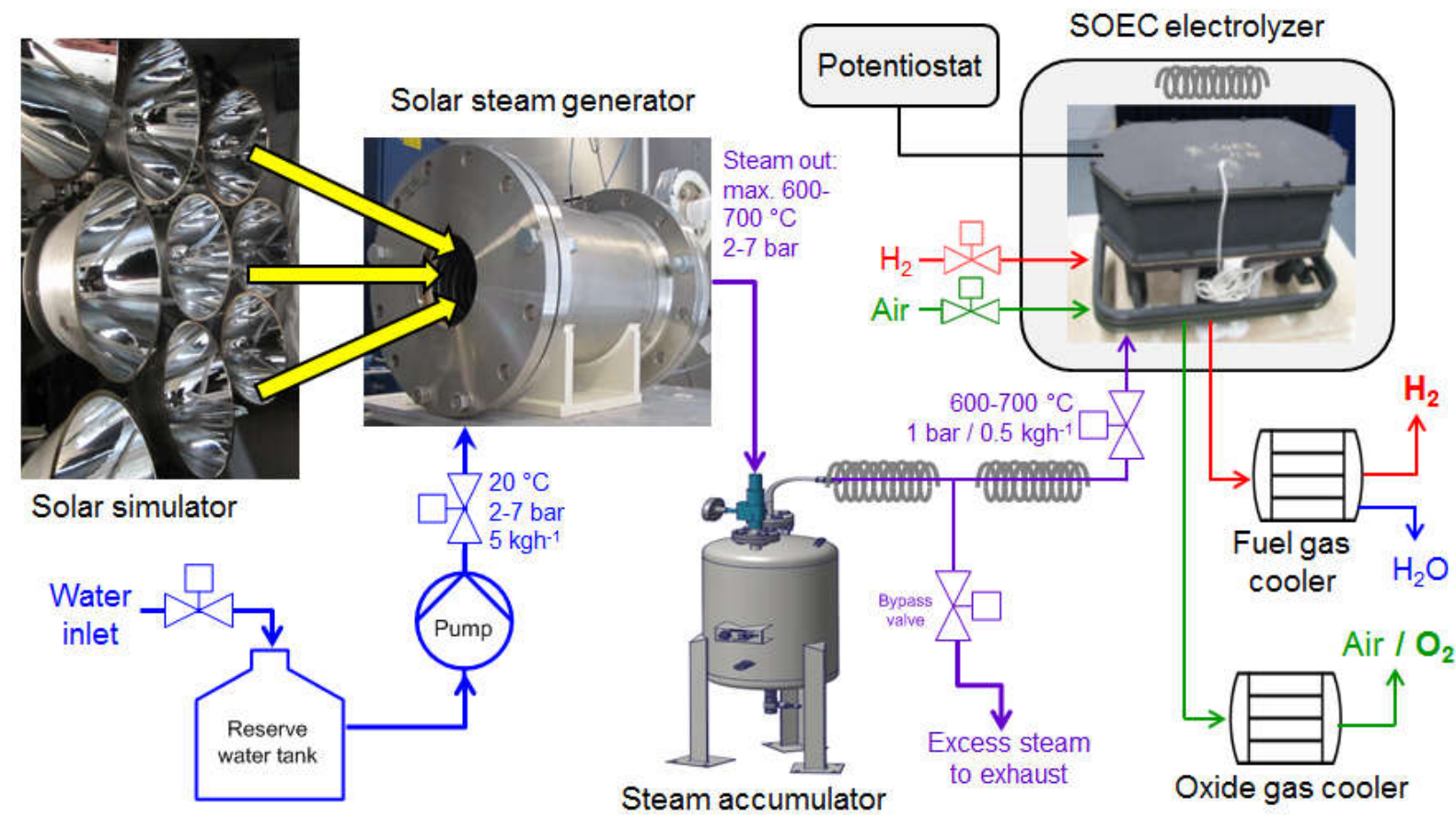

Figure 2: Experimental setup of the solar heated solid oxide electrolyzer system for hydrogen production 


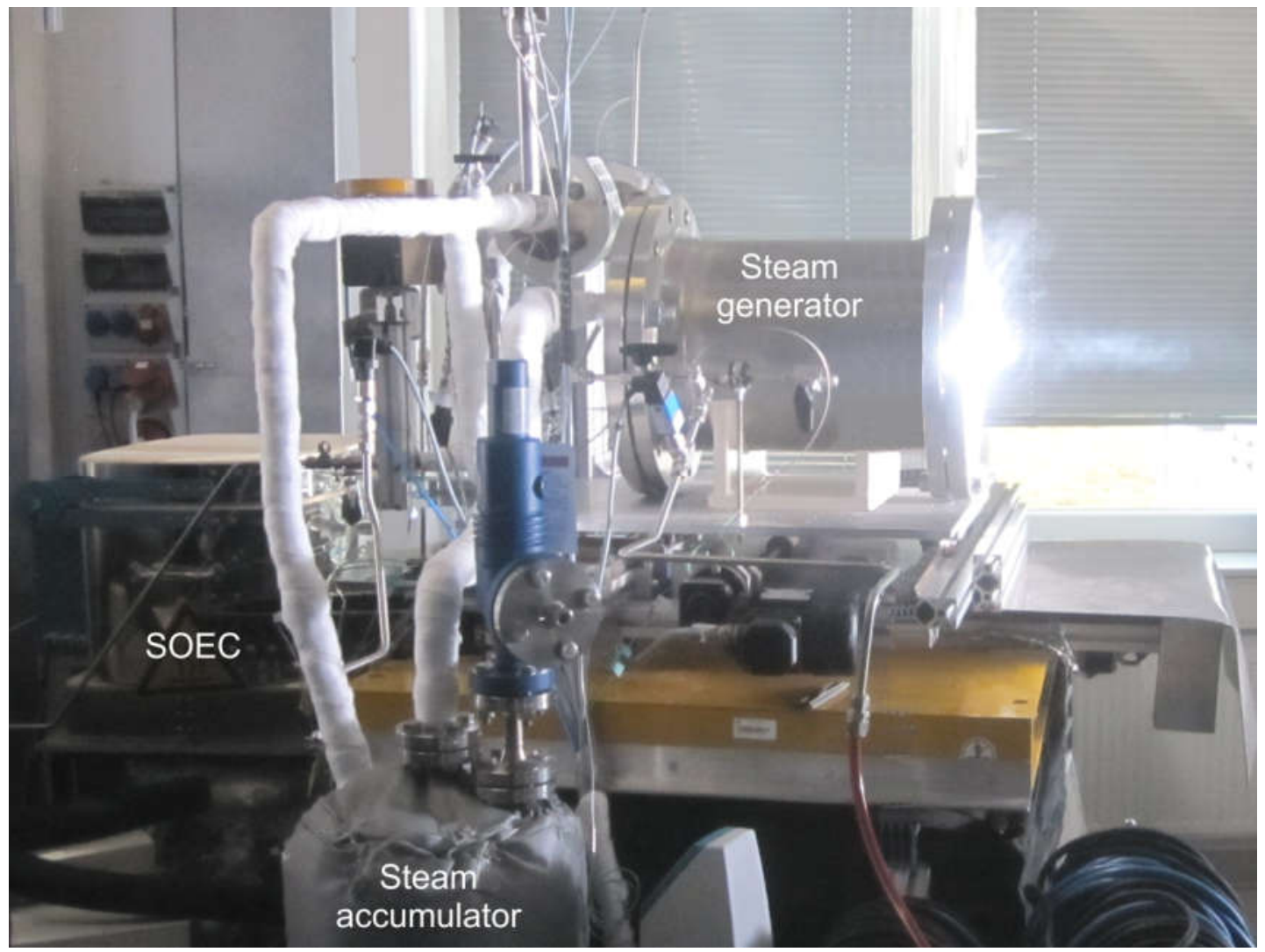

Figure 3: Photograph of SOEC electrolyzer (left) and solar steam generator (right) during operation

\subsection{Solar simulator}

A xenon high flux solar simulator based on elliptical reflectors with 10 xenon short-arc lamps [14] is operated at DLR's premises in Cologne. These lamps offer high intensities and unfiltered spectrum which matches sensibly well to sunlight. The emitted radiation is feasible for a wide range of applications and can be added up to $20 \mathrm{~kW}$ power. This radiant power is concentrated up to $4 \mathrm{MWm}^{-2}$ on an area of $1 \mathrm{~cm}^{2}$ in the reflectors focal distance of $3 \mathrm{~m}$. The xenon high-flux solar simulator at DLR is used for exploration and testing new technologies where temperatures of above $2000^{\circ} \mathrm{C}$ are possible to be achieved. The focal point has been adjusted by thermal imaging and calibrated laser pointers. In Table 1 the technical data of the solar simulator are summarized. 
Table 1: Solar simulator's technical data

\begin{tabular}{|l|l|}
\hline Technical data & Description \\
\hline 10 xenon short-arc lamps with elliptical reflectors & Thorium-doped tungsten electrodes \\
\hline Electrical power per lamp $6 \mathrm{~kW}(\mathrm{U}=37 \mathrm{~V} ; \mathrm{I}=160 \mathrm{~A})$ & Operating pressure of lamp: $80 \mathrm{bar}$ \\
\hline Ignition voltage $\mathrm{U}_{\mathrm{i}}=40 \mathrm{kV}$ & Luminance $10,500 \mathrm{cdm}^{-2}$ \\
\hline Arc length: $9 \mathrm{~mm}(\mathrm{cold}) ; 7,5 \mathrm{~mm}$ (hot) & Magnetically stabilized arcs \\
\hline Optional: UV-A/B/C emission & Spectra similar to sunlight \\
\hline Concentration & 4,500 \\
\hline Maximum power & $20 \mathrm{~kW}$ \\
\hline Radiation flux density & $4.2 \mathrm{MWm}{ }^{-2}$ at $165 \mathrm{~A}$ rated current \\
\hline Dimension, $\mathrm{W}$ H & $4.5 \mathrm{~m} \mathrm{x} 3 \mathrm{~m}$ \\
\hline Weight & $800 \mathrm{~kg}$ \\
\hline Aperture & $6 \mathrm{~m}^{2}$ \\
\hline Reflectivity of the mirrors in new condition & 89 \\
\hline
\end{tabular}

\subsection{Solar steam generator}

A spiral solar receiver to be used as a solar steam generator has been designed, developed and adapted to the required specifications of the high temperature electrolyzer for the purpose of evaporating water that will supply steam to the SOEC electrolyzer stack (see Figure 2). The conical spiral solar steam generator is made from high temperature stainless steel grade 1.4841 (10 $\mathrm{mm}$ in diameter and $1.5 \mathrm{~mm}$ in thickness). The conical shape of the spiral tube helps to improve the heat flux distribution. The concentrated incident solar radiation on the receiver cavity is absorbed by the spiral tube which in turn acts as heat exchanger by transferring the heat absorbed to water (loaded from the front) in order to convert it into superheated steam. The spiral tube is located inside an insulation housing ("PROMAFORM 1600" with low thermal conductivity of $0.22 \mathrm{Wm}^{-1} \cdot \mathrm{K}^{-1}$ at $1000{ }^{\circ} \mathrm{C}$ ) fabricated to hold it in place and to prevent heat losses. The inlet water, outlet steam and the surface temperatures of the steam generator are measured using K-type thermocouples. In order to prevent thermocouples from being directly irradiated, while facilitating their replacement, they are inserted into protective fittings which are welded on the receiver tube. 


\subsection{Water supply system}

The water inlet is purified with an ion exchanger before entering the reserve water tank. The tank is used to avoid possible fluctuations with respect to pressure and mass flow rate to the water pump and the flow controller. The water level in the tank is maintained at a constant level by measuring the height and refilled automatically from the water inlet using a solenoid valve. Based on the dimensions of the solar steam generator, the water flow is maintained at $5 \mathrm{kgh}^{-1}$ and inlet pressure is maintained at the desired level using a pressure booster.

\subsection{Steam accumulator}

Superheated steam outlet from the solar steam generator is fed into a steam accumulator for storage (see Figure 2), in order to limit fluctuations with respect to temperature and pressure. In real condition the steam accumulator will also serve to limit the fluctuations caused due to the intermittent solar radiation (for instance by cloud passage). The vessel with a volume of 33 liters is designed to operate at a maximum temperature and pressure of $400^{\circ} \mathrm{C}$ and 25 bar, respectively. Furthermore, the vessel is robust to withstand 11,500 full load cycles between ambient conditions and the maximum operating conditions. It can be operated for accumulation of both the superheated steam as well as the saturated steam. However, the amount of steam accumulated will be much higher with the variation of saturated steam. Moreover, it has to be noted that the steam accumulator was located about $100 \mathrm{~cm}$ away from the steam generator outlet and was not thermally insolated in an optimum way (Figure 3).

\subsection{Solid oxide electrolyzer}

The solid oxide electrolyzer (SOEC) stack is located inside a furnace/hot box and consists of 12 repeat units (RU) which are connected in series. The stack was fabricated and supplied by "SOLIDPower" (Mezzolombardo, Italy) and contains so-called fuel electrode supported cells with an active area of $80 \mathrm{~cm}^{2}$. The stack uses an internal gas manifold for the fuel gas and an external manifold for the air [15].

All stack operating parameters except the steam supply are controlled and measured with a control rack. Each stack RU has separate probes for voltage measurement. This allows monitoring of possible inhomogeneity inside the stack. Six thermocouples measure gas inlet and outlet temperatures as well as 
stack bottom and top temperatures. Steam from the steam accumulator which is mixed with $10 \%$ of $\mathrm{H}_{2}$ and air is fed to the stack from the bottom. The small amount of $\mathrm{H}_{2}$ prevents the stack from reoxidation. In order to minimize thermal stresses in the stack caused by cold gases the respective inlet tubes are heated externally with heating hoses and inside the furnace with a helix before entering the stack. By applying a voltage to the stack with the potentiostat steam is electrolyzed to $\mathrm{H}_{2}$ and $\mathrm{O}_{2}$. Both gas streams are cooled in gas coolers where also the remaining water was removed from the fuel gas. All process gases are vented to the environment.

In order to determine the optimum steam conversion rate a current-voltage $(\mathrm{j} V)$ curve with increasing and decreasing current density was measured. The jV-curve was measured according to the pre-normative test procedure "Test Module 03: Current-voltage characteristics" [16] of the SOCTESQA project [17]. Moreover, the system stability was measured by operating the stack at constant steam supply and constant electrical current density. For safety reasons, this steady-state operation could only be measured during daytime for about $5 \mathrm{~h}$ with manned control of the system.

\section{Results and Discussion}

\subsection{Solar steam generation}

Selected results of the test operation of the solar steam generation and the storage subsystem are presented in Figures 4 and 5. In Figure 4 the relevant mass flow of water/steam through the solar steam generator and in Figure 5 measured temperatures of the system are presented.

The complete test can be distinguished in three phases. In the first phase $(0-2 h)$ the system was heated up and the operating conditions were optimized. During the start-up concentrated solar energy was irradiated on the steam generator and the SOEC stack was heated up. In order to prevent the prototype system from overheating and due to safety issues for the first tests only three lamps of the solar simulator were activated. This provided a total power of $5.66 \mathrm{~kW}$ onto the receiver aperture of $0.0201 \mathrm{~m}^{2}$ (diameter of $16 \mathrm{~cm}$ ) which corresponds to an average flux of $282 \mathrm{kWm}^{-2}$ on the receiver aperture. After the start up a steam mass flow of $5 \mathrm{kgh}^{-1}$ was delivered by the steam generator which corresponds to volumetric flow of 
104 standard liter per minute (slpm). During the parameter optimization phase strong fluctuations of the steam mass flow through the steam generator occur (see Figure 4). With ongoing operation of the system and parameter optimization, e.g. the settings for water mass flow, pressures, temperatures and valves, the steam mass flow stability could be optimized successfully. However, the absolute steam flow variations still remained in the range of $4.7-5.3 \mathrm{kgh}^{-1}$. The second operating phase $(2 \mathrm{~h}-3.5 \mathrm{~h})$ focused on the first SOEC electrolyzer operation and the simulation of a cloud passage on the solar heat generator. After $2 \mathrm{~h}$ of operation the first current-voltage curve of the SOEC electrolyzer was measured (see Figures 6 and 7 ). The cloud passage interruption after $3 \mathrm{~h}$ of operation was implemented in order to analyze the thermal behavior of the system (Figure 5) during the standby time as in a "real-life" condition. The cloud formation with approximately 30 minutes duration was simulated by switching off both the solar simulator and the water/steam flow through the steam generator. In the third operating phase after $3.5 \mathrm{~h}$ the system was operated under steady-state conditions in order to investigate its stability behavior. The corresponding results of the electrochemical behavior of the SOEC electrolyzer are depicted in Figure 8 . After $8.5 \mathrm{~h}$ of operation the system was shut-down.

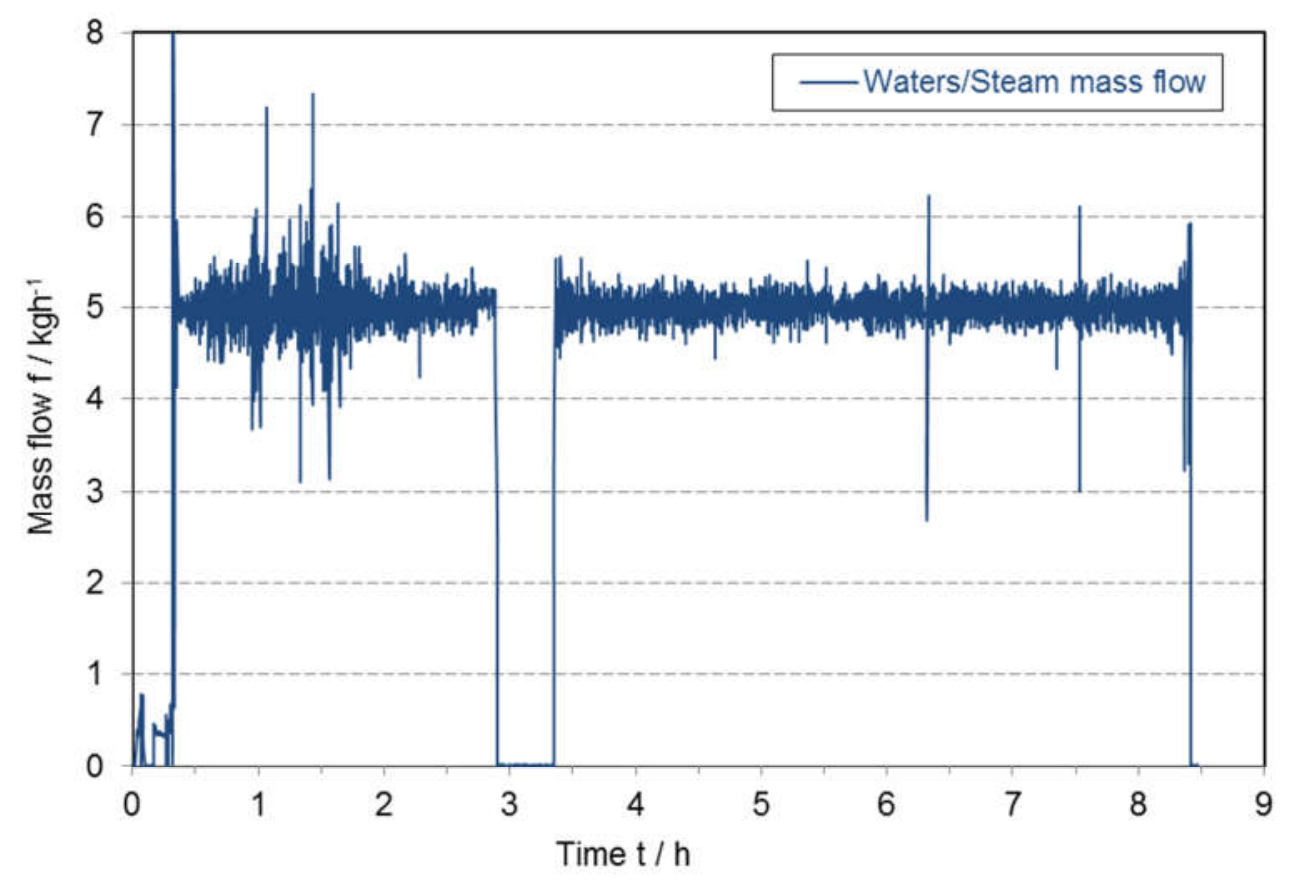

Figure 4: Mass flow of water/steam through the solar steam generator 
Figure 5 shows the most important temperatures of the solar steam generation. During the start-up a rapid increase of the steam generator outlet temperature from $25^{\circ} \mathrm{C}$ to $470{ }^{\circ} \mathrm{C}$ can be observed. This proves a highly dynamic behavior of the solar steam generator. As the average inlet temperature of water was $25^{\circ} \mathrm{C}$ the overall temperature increase through the reactor was about $375^{\circ} \mathrm{C}-425^{\circ} \mathrm{C}$. After the start-up the steam generator outlet temperature is in the range of $450{ }^{\circ} \mathrm{C}$ with fluctuations of $20^{\circ} \mathrm{C}-30^{\circ} \mathrm{C}$. The behavior of the temperatures of the steam accumulator and of the steam from the accumulator to the electrolyzer is strongly dependent on the thermal insulation and the tube heating power, respectively. Therefore, these components show a less dynamic behavior during the start-up procedure. Moreover, Figure 5 shows that during operation of the system the superheated steam of the solar steam generator cooled down to about $150{ }^{\circ} \mathrm{C}$ in the steam accumulator and was heated up afterwards in the tubes to the SOEC electrolyzer to $600{ }^{\circ} \mathrm{C}$. Both the steam accumulator and the steam supply from the accumulator to the SOEC electrolyzer reveal much more stable temperature behavior compared to the solar steam generator. Only a minor pressure difference was measured between steam generator inlet and steam accumulator. In the presented test the pressure to the electrolyzer system was kept constant at atmospheric pressure.

During the cloud passage simulation after interruption of the irradiation a rapid temperature decrease in the steam generator to below $50^{\circ} \mathrm{C}$ can be observed within a few minutes. After continuation of irradiation the operating temperature was reached again after a few minutes. The temperature in the steam accumulator rises to the temperature of evaporation of the present pressure within one hour and then rises with pressure until it remains nearly constant. This indicates that during the entire operation period liquid water is present in the steam accumulator. It can be seen that the temperature in the steam accumulator only slightly decreased during the 30 minutes interruption and increased rapidly to the original value afterwards. This illustrates the value of implementing a steam accumulator into the system for buffering fluctuations in solar radiation supply. 


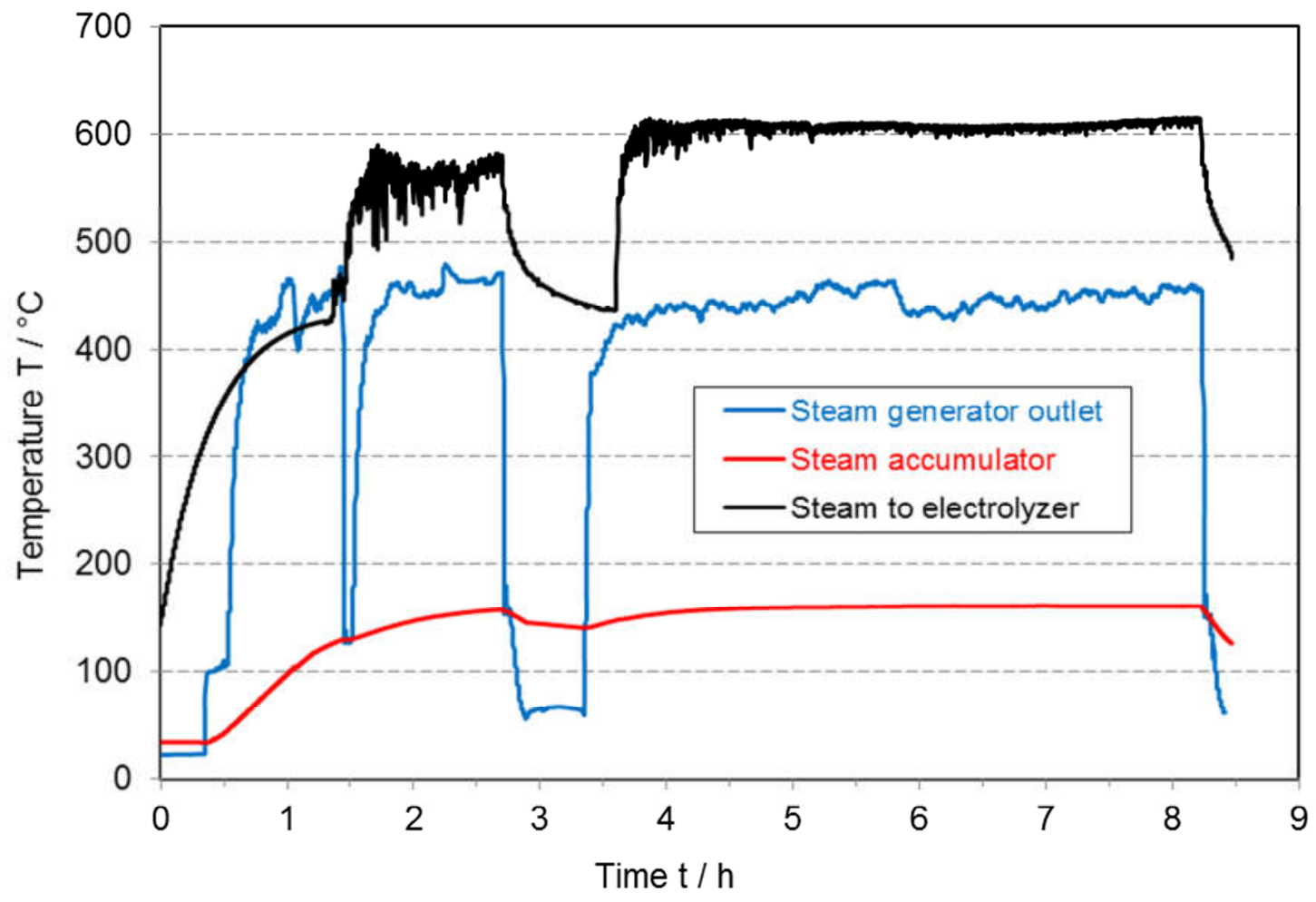

Figure 5: Relevant temperature measurements in the solar steam generation system

\subsection{Solid oxide electrolysis}

During the start-up of the system the SOEC stack was heated up to the desired operating temperature of $770^{\circ} \mathrm{C}$ with hot steam gas from the steam accumulator and additional peripheral furnace heating. Figure 6 shows the current-voltage behavior and selected temperatures of the SOEC electrolyzer stack after the startup of the system. Note that conventionally for SOEC electrolysis operation the current density is negative in order to distinguish from the SOFC fuel cell mode. The stack was supplied with a mixture of $1.4 \mathrm{slpm}$ of $\mathrm{H}_{2}$ and $12.0 \mathrm{slpm}$ of steam which was fed from the steam accumulator. The fuel gas flow and composition of $90 \% \mathrm{H}_{2} \mathrm{O} / 10 \% \mathrm{H}_{2}$ was adapted to the stack size which was recommended by the stack manufacturer. The hydrogen was added as protection gas to prevent the Ni+YSZ fuel electrodes of the cells in the SOEC electrolyzer stack from undesired oxidation to NiO+YSZ. Filtered and dried air from a compressor was fed to the air electrodes of the stack. 


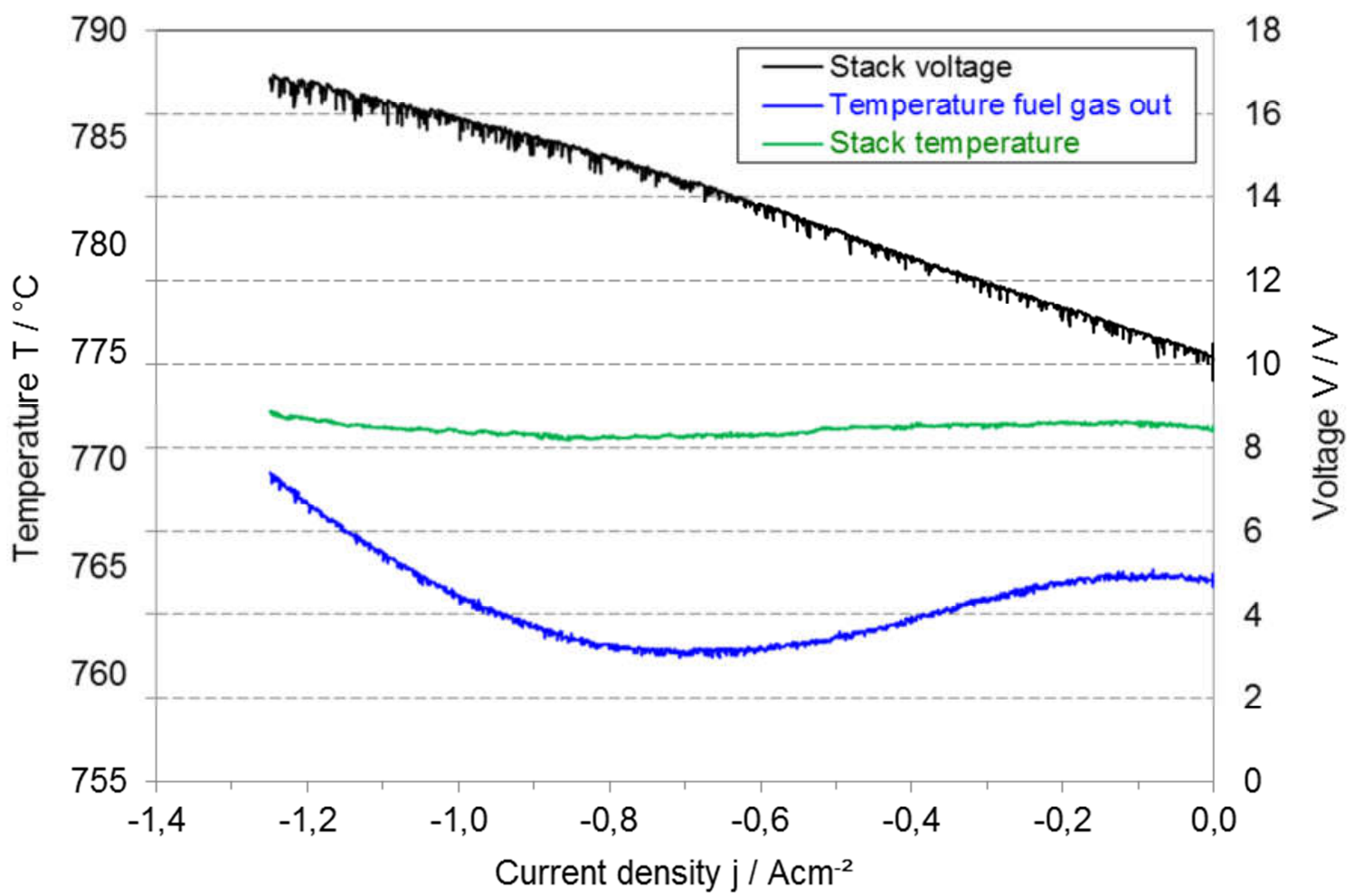

Figure 6: Current-voltage behavior of 12 -cell SOEC stack at $770^{\circ} \mathrm{C}$ with $12.0 \mathrm{slpm} \mathrm{H}_{2} \mathrm{O}+1.4 \mathrm{slpm} \mathrm{H}_{2}$ and 20 slpm air

The open circuit voltage (OCV) of the stack with the gas composition of $90 \% \mathrm{H}_{2} \mathrm{O}+10 \% \mathrm{H}_{2}$ was $10.3 \mathrm{~V}$ which is in good agreement with the theoretical value calculated with the Nernst equation [18]. This indicates good gas tightness and high quality of the stack sealing. The stack voltage increases almost linearly with increasing current density. This behavior is well-known for SOEC and can be attributed to low activation polarization resistances of the fuel and air electrodes (see Eq. 1 and 2). Moreover, electrochemical impedance spectra have shown almost constant polarization resistances with increasing current density [19]. However, strong voltage fluctuations in the jV-curve can be observed which are caused by the above mentioned steam mass flow instabilities from the steam generator (see Figure 4). At a current density of $-1.25 \mathrm{Acm}^{-2}$ the electrolysis voltage is approximately $16.5 \mathrm{~V}$ which results in an electrolysis power of $-1.65 \mathrm{~kW}$. At this operation point a steam conversion rate of $70 \%$ was achieved which corresponds to a production of 8.4 slpm of hydrogen. This results in an electrical stack efficiency of $93 \%$ that is based on the lower heating value of $\mathrm{H}_{2}$. Even at the higher electrical current the average 
electrolysis voltage of $1.4 \mathrm{~V}$ per $\mathrm{RU}$ was below the maximum voltage limit of $1.6 \mathrm{~V}$ given by the stack manufacturer. Hence, even higher stack electrolysis performance is feasible. The temperatures of the stack and outlet fuel gas decrease with increasing current density due to the endothermic water splitting reaction. After the temperature minimum at a current density of $-0.7 \mathrm{Acm}^{-2}$ the temperature increases and the thermo-neutral point (TNP) is reached at about $-1.0 \mathrm{Acm}^{-2}$. At the TNP the measured electrolysis voltage per $\mathrm{RU}$ is $1.32 \mathrm{~V}$ which is in good agreement with the theoretical value of $1.285 \mathrm{~V}$ [18]. At current densities higher than the TNP the stack is operated in the exothermal mode which results in a further increase of the stack and gas temperatures.

Another important issue of the electrochemical performance of the system is the electrochemical homogeneity of the SOEC stack. Figure 7 shows the characteristic electrochemical values of the 12 stack repeat units, specifically OCVs, electrolysis voltages and area specific resistances (ASR), at $70 \%$ steam conversion rate which were extracted from the jV-behavior of Figure 6.

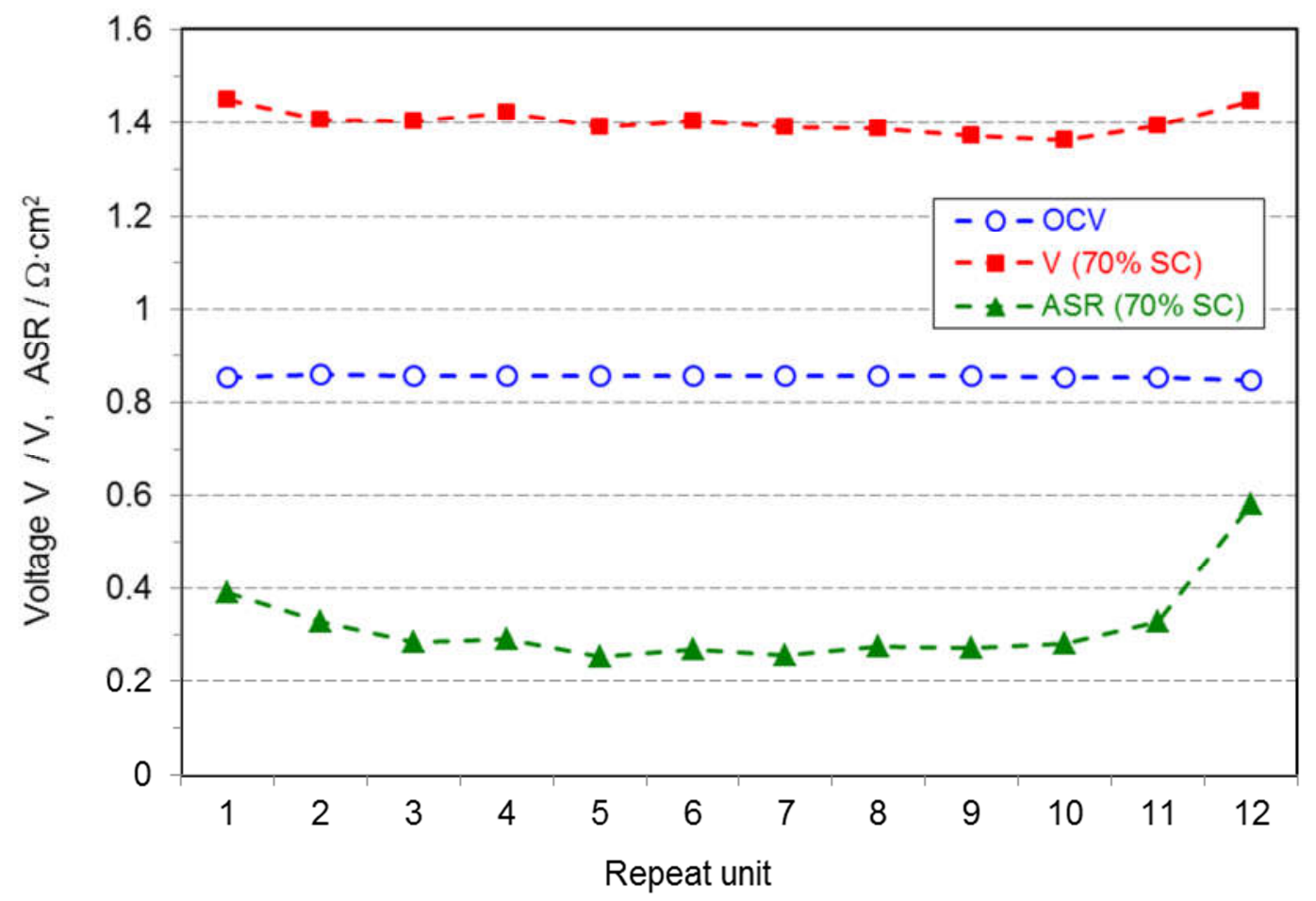

Figure 7: Characteristic electrochemical values of the repeat units of the SOEC stack at $770^{\circ} \mathrm{C}$ with 12.0 slpm $\mathrm{H}_{2} \mathrm{O}+1.4$ slpm $\mathrm{H}_{2}$ and 20 slpm air 
The OCVs of the 12 stack repeat units are very uniform with a standard deviation of $2.5 \mathrm{mV}$ from the mean value of $0.855 \mathrm{~V}$. This indicates high quality and reproducibility of the corresponding gas sealing of the different repeat units. The voltages and ASRs of the RUs at $70 \%$ steam conversion are in the range of $1.4 \mathrm{~V}$ and $0.3 \Omega \cdot \mathrm{cm}^{2}$, respectively. These values are in good agreement with SOEC stack literature results of other research groups $[20,21]$. However, in contrast to the OCV, higher differences in the electrolysis voltages and in the ASRs of the RUs can be observed. Such results indicate that values of the voltage and ASRs are higher at the bottom and top than in the middle of the stack. This behavior which is well-known especially in SOFC stacks is called "stack edge effect" and can be explained by the lower temperature of the bottom and top region compared to the middle core of the stack [22]. The overall minor differences of the voltages and ASRs of the RUs are caused by the above described steam supply variations (see Figure 4). It can be summarized that the stack shows a high homogeneity level among the different repeat units.

After the performance test of the system the stack was operated for $4 \mathrm{~h}$ in steady-state at a current density of $-1.0 \mathrm{Acm}^{-2}$ in order to investigate the stability behavior. Figure 8 shows the stack voltage, the electrical current and the temperature of the outlet fuel gas as a function of time. 


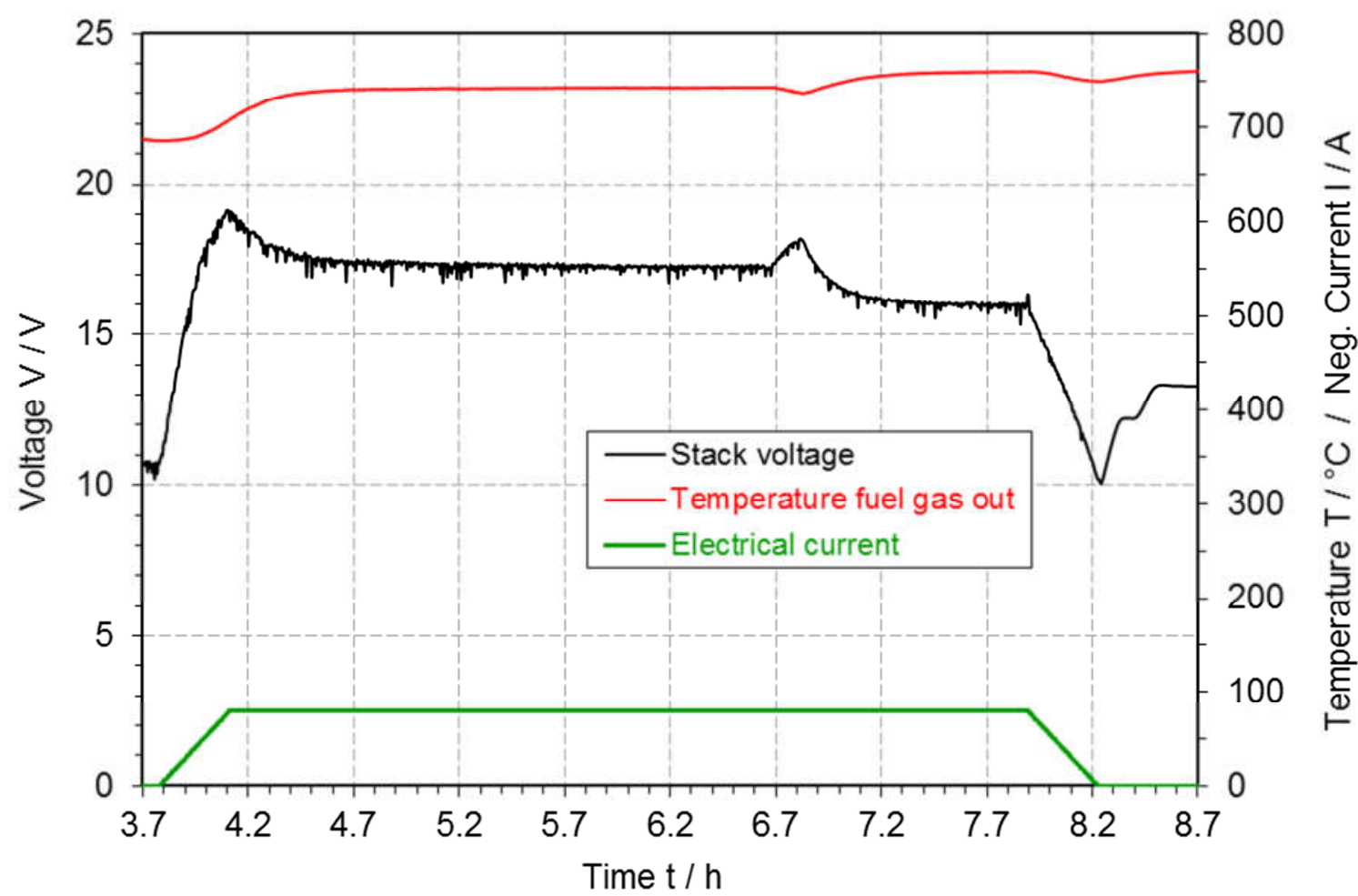

Figure 8: Behavior of the SOEC stack during steady-state operation for $4 \mathrm{~h}$ at $700^{\circ} \mathrm{C}$ and $-1.0 \mathrm{Acm}^{-2}$

After the maximum current of $-80 \mathrm{~A}\left(-1 \mathrm{Acm}^{-2}\right)$ was reached the stack voltage slowly decreased from approx. $19 \mathrm{~V}$ to $17.4 \mathrm{~V}$ at $4.7 \mathrm{~h}$ of operation which is caused by the temperature increase in the stack. Due to the high thermal mass of the stack even in the following operation phase a slow and continuous increase in the temperature of the outlet fuel gas and of the stack itself can be observed. This effect further decreased the electrolysis stack voltage by $0.1 \mathrm{~V}$. After about $7 \mathrm{~h}$ of operation the steam mass flow to the stack was readjusted to $12.0 \mathrm{slpm}$ which induced a short electrolysis voltage peak with a subsequent increase of the temperatures of the inlet steam (Figure 5) and of the outlet fuel gas (Figure 8). After the steam flow has stabilized the higher stack temperature led to a drop in the electrolysis voltage to approximately $16 \mathrm{~V}$. After steady-state operation of the SOEC stack at $-1 \mathrm{Acm}^{-2}$ for 4 hours the electrolysis operation was stopped and the system was shut down after approximately 8 hours of total operation. 


\subsection{Further system optimization}

The prototype system used needs a number of potential improvements to be done which will be tackled within further development work. Firstly, the control of the solar steam generator has to be optimized in order to minimize the steam supply instabilities. Secondly, the positioning of the system components will be rearranged closer together and their thermal insulation will be improved in order to minimize peripheral electrical heated pipes. Finally, a new high-temperature steam accumulator with storage temperatures in the range of $700^{\circ} \mathrm{C}$ and low thermal losses will be developed. These system optimizations will allow for running the next experiments with higher solar irradiation heat input and thus significantly increasing the overall system efficiency.

\section{Conclusions}

In order to integrate solar heat for the evaporation and superheating of water in high-temperature solid oxide electrolysis a solar simulator and a solar steam generator were successfully connected to a 12-cell SOEC stack. At $770^{\circ} \mathrm{C}$ and a current density of $-1.25 \mathrm{Acm}^{-2}$ approximately $8 \mathrm{slpm}$ hydrogen were produced with a steam conversion rate of $70 \%$. At these operating conditions an electrical stack efficiency of $93 \%$ was achieved. Steady-state operation at $700^{\circ} \mathrm{C}$ and $-1.0 \mathrm{Acm}^{-2}$ was performed for 4 hours in total demonstrating that SOEC operation with solar heat is feasible and promising. The experiment showed strong interaction between stack behavior and steam mass flow. It is therefore crucial to control the steam mass flow properly. Further system optimizations include the reduction of peripheral heated tubes, the increase of thermal insulation of the system components and the development of a high temperature steam accumulator. The experiment reported represents to the authors' knowledge the first successful integration of solar heat into commercial solid oxide electrolysis for highly efficient hydrogen production.

\section{Acknowledgement}

Financial support from DLR's basic funding for the project "Future Fuels" is gratefully acknowledged. The authors also thank Martin Thelen, Christian Willsch and Gerd Dibowski from the DLR solar furnace team for their support during the experiment. 


\section{References}

[1] V. Kondratenko, G. Mul, J. Baltrusaits, G.O. Larrazabal, J.P. Perez-Ramirez, Status and perspectives of $\mathrm{CO}_{2}$ conversion into fuels and chemicals by catalytic, photocatalytic and electrocatalytic processes, Energy \& Environmental Science 6 (2013) 3112-3135

[2] S.D. Ebbesen, S.H. Jensen, A. Hauch, M.B. Mogensen, High temperature electrolysis in alkaline, solid proton conducting cells, and solid oxide cells, Chemical Reviews 114 (2014) 10697-10734

[3] S.R. Foit, L. Dittrich, V. Vibhu, I.C. Vinke, R.A. Eichel, L.G.J. de Haart, Co-electrolysis, quo vadis?, ECS Transactions 78 (2017) 3139-3147

[4] W. Doenitz, R. Schmidberger, E. Steinheil, R. Streicher, Hydrogen production by high temperature electrolysis of water vapour, Int. J. Hydrogen Energy 5(1) (1980) 55-63

[5] W. Dönitz, E. Erdle, High temperature electrolysis of water vapour - status of development and perspective of application, Int. J. Hydrogen Energy 10(5) (1985) 291-295

[6] A.O Isenberg, Energy conversion via solid oxide electrolyte electrochemical cells at high temperatures, Solid State Ionics 3-4 (1981) 431-437

[7] S.H. Jensen, P.H. Larsen, M. Mogensen, Hydrogen and synthetic fuel production from renewable energy sources, Int. J. Hydrogen Energy 32 (2007) 3253-3257

[8] G. Schiller, A. Ansar, M. Lang, O. Patz, High temperature water electrolysis using metal supported solid oxide electrolyser cells (SOEC), J. Appl. Electrochem. 39 (2009) 293-301

[9] M.A. Laguna-Bercero, Recent advances in high temperature electrolysis using solid oxide fuel cells: A Review, J. Power Sources 203 (2012) 4-16

[10] J. Schefold, A. Brisse, F. Tietz, Nine thousand hours of operation of a solid oxide cell in steam electrolysis mode, J. of The Electrochem. Soc. 159 (2) (2012) A137-A144

[11] W. Schnurnberger, U. Wittstadt, H. Janßen, Wasserspaltung mit Strom und Wärme, Themenheft 2004: Wasserstoff und Brennstoffzellen - Energieforschung im Verbund (2004) 50-59

[12] A.S. Joshi, I. Dincer. B.V. Reddy, Solar hydrogen: A comparative performance assessment, Int. J. Hydrogen Energy 36 (2011) 11246-11257 
[13] M. Lin, S. Haussener, Techno-economic modelling and optimization of solar-driven hightemperature electrolysis systems, Solar Energy 155 (2017) 1389-1402

[14] A. Houaijia, S. Breuer, D. Thomey, C. Brosig, J.P. Säck, M. Roeb, C. Sattler; Solar hydrogen by high-temperature electrolysis: Flowsheeting and experimental analysis of a tube-type receiver concept for superheated steam production, Energy Procedia 49 (2014) 1960-1969

[15] SOFCpower, SOFCpower stack specification, Future Fuels project document (2014).

[16] G. de Marco et. al., Test Module 03: Current-voltage characteristics, SOCTESQA project document (2017) https://elib.dlr.de/119895/

[17] FCH-JU project "SOCTESQA": Solid Oxide Cell and Stack Testing, Safety and Quality Assurance (SOCTESQA), Project ID 621245, https://www.fch.europa.eu/project/solid-oxide-cell-and-stacktesting-safety-and-quality-assurance/

[18] Q. Fu et. al., Test Module 00: General SOC Testing Guidelines, SOCTESQA project document (2017) https://elib.dlr.de/119897/

[19] M. Lang, G. Braniek, S. Kurz, N. Muck, T. Schneider, Y. Zhang, Advanced electrochemical characterization of solid oxide electrolysis stacks (SOEC), Proc. $12^{\text {th }}$ European SOFC\&SOEC Forum, European Fuel Cell Forum, Lucerne-Adligenswil, Switzerland (2016) A1412

[20] Y. Zheng, Q. Li, T. Chen, C. Xu*, W. G. Wang, Quantitative contribution of resistance sources of components to stack performance for solid oxide electrolysis cells, Journal of Power Sources 274 (2015) 736-740

[21] Q. Fu, J. Schefold, A. Brisse, J. U. Nielsen, Durability Testing of a High-Temperature Steam Electrolyzer Stack at $700{ }^{\circ} \mathrm{C}$, Fuel Cells, 14 (3) (2014) 395-402

[22] M. Lang, C. Auer, G. Braniek, F. Wenz, F. Hauler, Understanding the Electrochemical Performance of SOFC Stacks, ECS Transactions, 68 (1) (2015) 2441-2451 